\title{
Cognitive and Neural Mechanisms Underlying Socioeconomic Gradients in Language Development: New Answers to Old Questions
}

\author{
$\ddot{O ̈ z l e m ~ E c e ~ D e m i r ~}^{1}$ and Aylin C. Küntay ${ }^{2,3}$ \\ ${ }^{1}$ Northwestern University, ${ }^{2}$ Koç University, and ${ }^{3}$ Utrecht University
}

ABSTRACT_Although researchers have studied disparities in early language development related to socioeconomic status (SES), it is unclear how early and through which mechanisms these differences emerge. As income inequality continues to widen across the world, it is crucial to examine the child-level mechanisms that mediate the effects of SES on individual differences in language development. A deeper understanding of the nature of the differences will allow development of more effective intervention techniques. In this article, we discuss work on child-level cognitive and neural mechanisms underlying the relation between SES and early language development. We discuss possible factors behind individual differences in child-level mechanisms and cascading effects of these differences. We conclude with recommendations for research.

KEYWORDS—language development; socioeconomic status; neural and cognitive mechanisms

Children from lower socioeconomic status (SES) fall behind their middle-class peers on many aspects of cognitive development

Özlem Ece Demir, Department of Communication Sciences \& Disorders, Northwestern University; Aylin C. Küntay, Department of Psychology, Koç University, Educational and Learning Sciences, Utrecht University.

We thank Lauren R. Applebaum and Matthew E. Lira for comments on earlier versions of the manuscript.

Correspondence concerning this article should be addressed to Özlem Ece Demir, Roxelyn and Richard Pepper Department of Communication Sciences \& Disorders, Northwestern University, 2240 Campus Drive, Frances Searle Building, Room 2-342, Evanston, IL 60208; e-mail: ece@northwestern.edu.

(C) 2014 The Authors

Child Development Perspectives $\odot 2014$ The Society for Research in Child Development DOI: $10.1111 /$ cdep.12069
(Bradley \& Corwyn, 2002; Brooks-Gunn \& Duncan, 1997; D'Angiulli, Lipina, \& Olesinska, 2012; Hackman \& Farah, 2009). Differences related to SES in young children's linguistic skills are well described (e.g., Hart \& Risley, 1995; Hoff, 2003), and are more pronounced than other cognitive domains (Hackman \& Farah, 2009).

Research on the SES-related disparities in language development does not commonly address the changes child-level mechanisms of language learning accrue in detrimental environments but emphasizes parent-level mechanisms underlying the effects of SES on language outcomes (Hoff, 2003). Given that early language predicts later reading skills and academic achievement, uncovering the child-level cognitive and neural mechanisms underlying the relation between SES and language development is crucial (NICHD Early Child Care Research Network, 2005). Such mechanistic understanding of child-level mechanisms can inform efforts to remediate the effects of low SES during the formative years of language development.

In this article, we first focus on the accumulating literature on the child-level cognitive and neural mechanisms that underlie the relation between SES and language development. We examine SES effects within the normal range (for effects of extreme neglect on child development, see Nelson, 2007). We then discuss factors behind individual differences in child-level mechanisms and longer term cascading effects of these early differences in later development. We end by suggesting new research to improve our understanding of SES gradients underlying children's language development.

\section{CHILD-LEVEL MECHANISMS THAT UNDERLIE THE EFFECTS OF SES ON LANGUAGE DEVELOPMENT}

By child-level mechanisms, we refer to the sociocognitive skills and neural processes underlying language learning, especially those that are affected by SES and that in turn predict individual differences in children's language outcomes. We discuss 
behavioral and neuroimaging studies examining three types of child-level mechanisms: communicative skills, speech- and language-processing skills, and attentional-control skills.

\section{Communicative Skills}

SES-related individual differences evident in communicative abilities emerge before speech and establish a base for children's later language development. Children start communicating through gestures before they use speech, and use of early gestures predicts later individual differences in language growth (Rowe \& Goldin-Meadow, 2009). SES affects children's early gesture production. For example, in a recent study, SES related to children's production of gestures but not spoken vocabulary size, at 14 months (Rowe \& Goldin-Meadow, 2009). Moreover, children's use of gestures predicted children's spoken vocabulary size at 54 months and mediated the relation between SES and vocabulary outcomes at 54 months. Other early communication behaviors such as vocalizations, eye-gaze, and joint attention are also influenced by parents' SES. In a study on the trajectory of children's communication-initiating behaviors between 6 and 40 months, parents' SES predicted the growth of children's initiating behaviors (Landry, Smith, Miller-Loncar, \& Swank, 1997). The frequency of children's initiating behaviors at 18 months predicted faster growth of later language skills.

Speech- and Language-Processing Skills

Infants' ability in processing speech sounds provides the basis for later developing language abilities. Foundational speech and language-processing skills include the ability to differentiate phonetic contrasts of the native language, lexical processing efficiency, and the ability to repeat words and nonwords. These early skills predict later vocabulary and syntactic development (Gathercole \& Baddeley, 1990; Hurtado, Marchman, \& Fernald, 2008; Junge, Cutler, \& Hagoort, 2010; Roy \& Chiat, 2013). SES may affect early-developing speech- and language-processing skills. In one study, SES-related differences were seen in 18- and 24-month-olds' lexical processing efficiency during real-time language comprehension (Fernald, Marchman, \& Weisleder, 2013). Lexical processing efficiency was measured by how quickly children turned toward the picture of a target object, as opposed to an alternative, when they heard the object's name. Children with higher SES looked at the named target sooner and were more accurate. In another study, 3- to 5-year-olds with lower SES performed less accurately than their higher SES peers on tasks in which they repeated words and nonwords (Roy \& Chiat, 2013).

A small but growing body of research uses neuroimaging to explore how SES affects the neural mechanisms underlying speech and language processing. These studies reveal SESrelated differences in brain structures and neural processes relevant to speech and language processing, especially in frontal (specifically inferior frontal and prefrontal areas) and temporal (specifically superior temporal and hippocampal regions) cortices in children. Individual differences in neural structure and function of these regions are important because they relate to concurrent and future language skills (Deniz Can, Richards, \& Kuhl, 2013; Mills, Coffey-Corina, \& Neville, 1997). Regarding differences in brain structure, SES is positively related to gray matter volume and gyrification in language-related regions, including the frontal, temporal, and hippocampal regions (Hair, 2013; Hanson et al., 2013; Jednoróg et al., 2012; Noble, Houston, Kan, \& Sowell, 2012; Raizada, Richards, Meltzoff, \& Kuhl, 2008). The effect of SES differences on brain structure is more pronounced for language-relevant regions, in frontal, temporal, and hippocampal areas, than for other brain areas (Jednoróg et al., 2012). Furthermore, SES effects on the volume of gray matter in frontal and temporal regions increase with age (Hanson et al., 2013; Noble et al., 2012). In a study that used electroencephalogram (EEG), 6- to 9-month-olds with lower SES had reduced baseline resting brain activity in frontal areas compared with their higherSES peers (Tomalski et al., 2013). Overall, the limited number of neuroimaging studies suggests that SES-related differences in language-related structures might emerge early in life, possibly before behavioral differences appear, and differences might increase with age.

Few studies have examined SES-related differences in neural processes during language tasks in children. In one, 3- to 8year-olds' event-related potential (ERP) responses to semantic and syntactic violations in spoken sentences were related to SES (Pakulak, Sanders, Paulsen, \& Neville, 2005). Both groups of children showed a negative ERP component for semantic violations (N400), but its amplitude and distribution varied according to SES. Both groups of children displayed a late positivity (P600) for syntactic violations, but only children with higher SES displayed an early negativity, suggesting that the effects of SES might be more pronounced for syntactic processing than for semantic processing. This early negativity reflects immediate use of incoming language input to guide online syntactic parsing and thus greater syntactic proficiency (Pakulak \& Neville, 2010). A similar relation between larger amplitude negativity to syntactic violations and childhood SES has been seen in adults (Pakulak \& Neville, 2010). In a study that used functional magnetic resonance imaging, SES correlated with greater hemispheric specialization of the left inferior frontal gyrus during a rhyming task for 5-year-olds, even after controlling for behavioral measures of language ability (Raizada et al., 2008). These studies suggest that children with higher SES might engage language-related regions of the brain more robustly and efficiently during language tasks.

\section{Attentional-Control Skills}

In addition to domain-specific speech and language-processing skills, domain-general attentional-control skills provide a basis for language development. Language learning requires selective attention to particular verbal stimuli for further processing while filtering out distracting environmental stimuli (NICHD Early 
Child Care Research Network, 2003; Stevens, Lauinger, \& Neville, 2009). Attentional control represents another domain in which SES effects are pronounced compared to other cognitive domains (Hackman \& Farah, 2009). As early as 6 months, children from higher SES backgrounds exhibit greater cognitive flexibility, respond to alerting cues more effectively, orient their attention, and resist interfering cues compared to their lower SES peers (Clearfield \& Niman, 2012; for reviews of broader SES effects on attentional skills, see Blair \& Raver, 2012; Mezzacappa, 2004). Moreover, SES-related variability in attentional skills partially accounts for the link between SES and language outcomes. For example, in a study of 1,002 children and their families (NICHD Early Child Care Research Network, 2003), SES predicted both children's ability to sustain attention and their language skills at 54 months. Ability to sustain attention was also correlated with children's language skills. When attention skills were controlled statistically, the relation between SES and language was reduced significantly.

In terms of differences in brain structure, the higher the SES of a child, the greater the volume of gray matter and cortical thickness in brain regions central to attentional skills, such as the frontal cortex (Hanson et al., 2013; Jednoróg et al., 2012; Lawson, Duda, Avants, Wu, \& Farah, 2013). SES differences are also observed in the neural underpinnings of attentional control in language-relevant tasks. In a study examining ERPs in 6to 9-year-olds that asked children to attend to tunes of a certain frequency (i.e., the attended channel) and respond when they detected a tone with different duration but to ignore different frequency tones (i.e., the unattended channel), the difference in the ERP waveforms to attended minus the unattended channel was used as a measure of selective attention (D'Angiulli, Herdman, Stapells, \& Hertzman, 2008). The difference was larger in children with higher SES than in those with lower SES, suggesting that children with lower SES allocated their attentional resources equally to the attended and the unattended channel. In another study, 3- to 8-year-olds were asked to attend to one of two narratives presented simultaneously and ERPs were compared to probe stimuli embedded in the two channels (Stevens et al., 2009). The difference in ERP waveforms between attended and unattended stimuli was greater for high-SES children than low-SES children. Similar to D'Angiulli and colleagues' (2008) results, the difference was driven by high-SES children responding more weakly to the unattended stimuli than did low-SES children, indicating greater ability to suppress distracting information. The two groups did not differ in the accuracy of their responses to the attended stimuli in either study.

In sum, behavioral studies highlight the predictive power of early attentional-control skills for later language development, and suggest that these skills might underlie the relation between SES effects and child language outcomes. Neuroimaging studies suggest that children with lower SES might have difficulties suppressing irrelevant information efficiently, even when behavioral measures might not reveal SES differences.

\section{CONCLUSIONS AND LOOKING AHEAD}

In the article, we reviewed behavioral and neuroimaging studies that are starting to provide a more detailed and complex picture of the mechanisms underlying the relations between SES and language outcomes. These studies reveal that early communicative skills and speech and language-input processing skills are influenced by children's social context starting at an early age. Studies also show that domain-general attentional-control skills might contribute to SES effects on language development. What factors might explain individual differences in child-level mechanisms, and what are the longitudinal and cascading effects of these individual differences?

\section{Factors Behind Child-Level Mechanisms}

High SES refers to a bundle of characteristics that include parents' cognitive stimulation, material wealth, occupation, access to education, high-quality neighborhoods, social networks, and reduced stress, among others (Bradley \& Corwyn, 2002; BrooksGunn \& Duncan, 1997; Hackman \& Farah, 2009; for a review on the effects of different aspects of SES, see Duncan \& Magnuson, 2012). For a long time, researchers have been challenged to pinpoint the exact causal processes affecting language development among many interrelated characteristics associated with SES. Economic investment theory, which emphasizes the availability of material resources (Becker, 1981), has been pitted against family stress theory, which highlights parents' stress (McLoyd, 1998). Both theories invoke parent-level factors as causal processes. Researchers have identified parents' cognitive stimulation, specifically child-directed speech, as a mediator of SES effects on children's language knowledge (Hart \& Risley, 1995; Hoff, 2003; Huttenlocher, Waterfall, Vasilyeva, Vevea, \& Hedges, 2010).

Parents' cognitive stimulation relates to individual differences in child-level mechanisms underlying the relation between SES and language outcomes, as well. In terms of speech-processing skills, for example, individual differences in the quantity and quality of speech children receive from their mothers at 18 months relate positively to children's lexical-processing efficiency at 24 months (Hurtado et al., 2008; Weisleder \& Fernald, 2013). In terms of attentional-control skills, parents' cognitive stimulation and responsiveness influence children's attentional abilities starting from infancy (NICHD Early Child Care Research Network, 2003). In one study, family-based intervention programs in which parents were trained to engage in attentional exercises with their children led to changes in children's selective attention (Neville et al., 2013). In the study, children's ERP responses to probe stimuli embedded in stories in attended versus unattended auditory channels were measured before and after the training. Children in the training group showed greater ERP signal enhancement in their neural response to attended stimuli after training than children in a comparison group. The study also highlighted that SES differences in neural functions are not immutable. Less is known 
about the factors behind child-level neural mechanisms underlying language development, but maternal nurturance and support in early childhood predicts school-age gray matter volume in the left hippocampus, an area central for memory and also language learning (Luby et al., 2012).

\section{Longitudinal and Cascading Effects of Child-Level Mechanisms}

Traditionally, SES effects on children's development have been conceptualized as unidirectional, but today they are interpreted according to transactional and dynamic systems views, which acknowledge complex causal relations between SES and developmental outcomes (for a review of these approaches, see Lewis \& Mayes, 2012; Sameroff, 2010; Van Geert, 2011). According to these views, early differences in child-level mechanisms might have cascading effects on children's later language development. As child-level mechanisms for language learning improve with higher SES, children might receive even richer feedback and input from their environment, and might be more equipped to process input, benefiting later language learning. Indeed, early-emerging SES-related differences in language development persist over time. Low-SES children who start behind do not catch up, and the early delays stay stable or increase with age (Hoff, 2013; NICHD Early Child Care Research Network, 2003; Roy \& Chiat, 2013). Supporting the first mechanism, parents adapt their language to the language level of their child and modify their interactions as the child develops (Huttenlocher, Vasilyeva, Waterfall, Vevea, \& Hedges, 2007). For example, in a study of mutual adaptation in the language of parents and their 1- to 3-year-olds over a few months, as the child's language skills changed, parents changed the adaptation of their language (word types and mean length of utterances) according to the child's language level (Van Dijk et al., 2013). Supporting the second mechanism, initial differences in child-level mechanisms might "enhance the efficiency with which children apprehend the fine-grained regularities that underlie the structure of their native language and form the foundation for continued lexical and grammatical growth" (Hurtado et al., 2008, p. 38). Within a low-SES sample, children's processing efficiency mediated the relation between parental input and children's vocabulary outcomes (Hurtado et al., 2008), suggesting that speed of lexical access to known words facilitates learning new words. Early advantages in vocabulary learning might have implications for other aspects of language learning, such as syntax.

\section{Looking Ahead}

Studying the effects of SES on children within a dynamic framework requires appropriate statistical models, which are still being developed. Equivalency of measures across development is a problem for longitudinal research. However, studies examining children's growth trajectories might reveal more information about cascading SES differences than focusing on a single time point. Information about the dynamic relations between the child and the environment can only be revealed through such longitudinal studies, assessing many aspects of the child's environment, many child-level mechanisms, and many child outcomes. Such studies could also explore the protective factors that promote resilience in lower SES children who perform similarly to their higher SES peers. Research on SES effects on language development should identify other child-level mechanisms, too. The lst year of life is underexplored, although communicative skills already start showing individual differentiation that early.

A few neuroimaging studies start to provide specificity regarding which systems are structurally and functionally implicated in SES-related differences in behavior. Neuroimaging studies need to interpret such structural and functional neural differences between different SES groups. Whether such differences should be interpreted to indicate delays, deficits, or adaptations is under discussion (D'Angiulli et al., 2012; Hackman \& Farah, 2009; Hoff, 2013). Differences in child-level mechanisms might look like adaptations in the short run, but ultimately prove detrimental in the long run, as is seen for the effects of stress reactivity on executive function (Blair \& Raver, 2012). Given that SES effects might not be uniform across ages and cognitive domains, longitudinal studies should characterize the different brain networks higher versus lower SES children rely on starting from the early years and link these to children's language outcomes over time. Through these designs, researchers could examine whether neuroimaging measures can predict growth of language skills, over and above the behavioral measures, and identify which neural organizations are associated with optimal versus suboptimal language outcomes.

The emerging body of literature we review in this article highlights the need to examine SES effects at many levels of organization through collaborations between developmental and cognitive psychologists and neuroscientists. By uncovering early child-level mechanisms that lead to competent and robust language development early in life, we can lay the groundwork for determining how early and in what ways intervention programs can remedy social disparities in language development.

\section{REFERENCES}

Becker, G. S. (1981). A treatise on the family. Cambridge, MA: Harvard University Press.

Blair, C., \& Raver, C. C. (2012). Child development in the context of adversity: Experiential canalization of brain and behavior. American Psychologist, 67, 309-318. doi:10.1037/a0027493

Bradley, R. H., \& Corwyn, R. F. (2002). Socioeconomic development and child development. Annual Review of Psychology, 53, 371399. doi:10.1146/annurev.psych.53.100901.135233

Brooks-Gunn, J., \& Duncan, G. J. (1997). The effects of poverty on children. The Future of Children, 7, 55-71. doi:10.2307/1602387

Clearfield, M. W., \& Niman, L. C. (2012). SES affects infant cognitive flexibility. Infant Behavior \& Development, 35, 29-35. doi:10.1016/ j.infbeh.2011.09.007 
D’Angiulli, A., Herdman, A., Stapells, D., \& Hertzman, C. (2008). Children's event-related potentials of auditory selective attention vary with their socioeconomic status. Neuropsychology, 22, 293300. doi:10.1037/0894-4105.22.3.293

D’Angiulli, A., Lipina, S. J., \& Olesinska, A. (2012). Explicit and implicit issues in the developmental cognitive neuroscience of social inequality. Frontiers in Human Neuroscience, 6, 254. doi:10.3389/ fnhum.2012.00254

Deniz Can, D., Richards, T., \& Kuhl, P. K. (2013). Early gray-matter and white-matter concentration in infancy predict later language skills: A whole brain voxel-based morphometry study. Brain and Language, 124, 34-44. doi:10.1016/j.bandl.2012.10.007

Duncan, G. J., \& Magnuson, K. (2012). Socioeconomic status and cognitive functioning: Moving from correlation to causation. Wiley Interdisciplinary Reviews: Cognitive Science, 3, 377-386. doi:10.1002/ wcs. 1176

Fernald, A., Marchman, V. A., \& Weisleder, A. (2013). SES differences in language processing skill and vocabulary are evident at 18 months. Developmental Science, 16, 234-248. doi:10.1111/desc. 12019

Gathercole, S. E., \& Baddeley, A. (1990). The role of phonological memory in vocabulary acquisition: A study of young children learning new names. British Journal of Psychology, 81, 439-454. doi:10. 1111/j.2044-8295.1990.tb02371.x

Hackman, D. A., \& Farah, M. J. (2009). Socioeconomic status and the developing brain. Trends in Cognitive Sciences, 13, 65-73. doi:10. 1016/j.tics.2008.11.003

Hair, N. (2013). Socioeconomic differences and academic achievement: Insights from the developing brain. Paper presented at the APPAM Annual Fall Research Conference, Washington, DC.

Hanson, J. L., Hair, N., Shen, D. G., Shi, F., Gilmore, J. H., Wolfe, B. L., \& Pollak, S. D. (2013). Family poverty affects the rate of human infant brain growth. PLoS One, 8, e80954. doi:10.1371/journal. pone.0080954

Hart, B., \& Risley, T. R. (1995). Meaningful differences in the everyday experience of young American children. Baltimore, MD: Brookes.

Hoff, E. (2003). The specificity of environmental influence: Socioeconomic status affects early vocabulary development via maternal speech. Child Development, 74, 1368-1378. doi:10.1111/ 1467-8624.00612

Hoff, E. (2013). Interpreting the early language trajectories of children from low-SES and language minority homes: Implications for closing achievement gaps. Developmental Psychology, 49, 414. doi:10.1037/a0027238

Hurtado, N., Marchman, V. A., \& Fernald, A. (2008). Does input influence uptake? Links between maternal talk, processing speed and vocabulary size in Spanish-learning children. Developmental Science, 11, F31-F39. doi:10.1111/j.1467-7687.2008.00768.x

Huttenlocher, J., Vasilyeva, M., Waterfall, H. R., Vevea, J. L., \& Hedges, L. V. (2007). The varieties of speech to young children. Developmental Psychology, 43, 1062-1083. doi:10.1037/ 0012-1649.43.5.1062

Huttenlocher, J., Waterfall, H., Vasilyeva, M., Vevea, J., \& Hedges, L. V. (2010). Sources of variability in children's language growth. Cognitive Psychology, 61, 343-365. doi:10.1016/j.cogpsych.2010. 08.002

Jednoróg, K., Altarelli, I., Monzalvo, K., Fluss, J., Dubois, J., Billard, C., ... Ramus, F. (2012). The influence of socioeconomic status on children's brain structure. PLoS One, 7, e42486. doi:10.1371/journal.pone.0042486
Junge, C., Cutler, A., \& Hagoort, P. (2010). Ability to segment words from speech as a precursor of later language development: Insights from electrophysiological responses in the infant brain. In Proceedings of the 20th International Congress on Acoustics (pp. 1-6). Sydney, Australia.

Landry, S. H., Smith, K. E., Miller-Loncar, C. L., \& Swank, P. R. (1997). Predicting cognitive-language and social growth curves from early maternal behaviors in children at varying degrees of biological risk. Developmental Psychology, 33, 1040-1053. doi:10. 1037/0012-1649.33.6.1040

Lawson, G. M., Duda, J. T., Avants, B. B., Wu, J., \& Farah, M. J. (2013). Associations between children's socioeconomic status and prefrontal cortical thickness. Developmental Science, 16, 641-652. doi:10.1111/desc.12096

Lewis, M., \& Mayes, L. C. (2012). The role of environments in development: An introduction. In L. Mayes \& M. Lewis (Eds.), The Cambridge handbook of environment in human development (pp. 1-12). New York, NY: Cambridge University Press.

Luby, J. L., Barch, D. M., Belden, A., Gaffrey, M. S., Tillman, R., Babb, C., ... Botteron, K. N. (2012). Maternal support in early childhood predicts larger hippocampal volumes at school age. Proceedings of the National Academy of Sciences of the United States of America, 109, 2854-2859. doi:10.1073/pnas.1118003109

McLoyd, V. C. (1998). Socioeconomic disadvantage and child development. American Psychologist, 53, 185-204. doi:10.1037/ 0003-066X.53.2.185

Mezzacappa, E. (2004). Alerting, orienting, and executive attention: Developmental properties and sociodemographic correlates in an epidemiological sample of young, urban children. Child Development, 75, 1373-1386. doi:10.1111/j.1467-8624.2004.00746.x

Mills, D. L., Coffey-Corina, S., \& Neville, H. J. (1997). Language comprehension and cerebral specialization from 13 to 20 months. Developmental Neuropsychology, 13, 397-445. doi:10.1080/ 87565649709540685

Nelson, C. A. (2007). A neurobiological perspective on early human deprivation. Child Development Perspectives, 1, 13-18. doi:10. 1111/j.1750-8606.2007.00004.x

Neville, H. J., Stevens, C., Pakulak, E., Bell, T. A., Fanning, J., Klein, S., \& Isbell, E. (2013). Family-based training program improves brain function, cognition, and behavior in lower socioeconomic status preschoolers. Proceedings of the National Academy of Sciences of the United States of America, 110, 12138-12143. doi:10.1073/ pnas. 1304437110

NICHD Early Child Care Research Network. (2003). Do children's attention processes mediate the link between family predictors and school readiness? Developmental Psychology, 39, 581-593. doi:10. 1037/0012-1649.39.3.581

NICHD Early Child Care Research Network. (2005). Pathways to reading: The role of oral language in the transition to reading. Developmental Psychology, 41, 428-442. doi:10.1037/0012-1649.41.2.428

Noble, K. G., Houston, S. M., Kan, E., \& Sowell, E. R. (2012). Neural correlates of socioeconomic status in the developing human brain. Developmental Science, 15, 516-527. doi:10.1111/j.1467-7687. 2012.01147.x

Pakulak, E., \& Neville, H. J. (2010). Proficiency differences in syntactic processing of monolingual native speakers indexed by eventrelated potentials. Journal of Cognitive Neuroscience, 22, 27282744. doi:10.1162/jocn.2009.2139

Pakulak, E., Sanders, L., Paulsen, D. J., \& Neville, H. (2005). Semantic and syntactic processing in children from different familial 
socioeconomic status as indexed by ERPs. Poster presented at the Cognitive Neuroscience Society, New York, NY.

Raizada, R. D. S., Richards, T. L., Meltzoff, A., \& Kuhl, P. K. (2008). Socioeconomic status predicts hemispheric specialisation of the left inferior frontal gyrus in young children. Neuroimage, 40, 13921401. doi:10.1016/j.neuroimage.2008.01.021

Rowe, M. L., \& Goldin-Meadow, S. (2009). Differences in early gesture explain SES disparities in child vocabulary size at school entry. Science, 323, 951-953. doi:10.1126/science.1167025

Roy, P., \& Chiat, S. (2013). Teasing apart disadvantage from disorder. In C. R. Marshall (Ed.), Current issues in developmental disorders (pp. 125-150). London, UK: Psychology Press.

Sameroff, A. (2010). A unified theory of development: A dialectic integration of nature and nurture. Child Development, 81, 6-22. doi:10. 1111/j.1467-8624.2009.01378.x

Stevens, C., Lauinger, B., \& Neville, H. (2009). Differences in the neural mechanisms of selective attention in children from different socioeconomic backgrounds: An event-related brain potential study.
Developmental Science, 12, 634-646. doi:10.1111/j.1467-7687. 2009.00807.x

Tomalski, P., Moore, D. G., Ribeiro, H., Axelsson, E. L., Murphy, E., Karmiloff-Smith, A., ... Kushnerenko, E. (2013). Socioeconomic status and functional brain development-Associations in early infancy. Developmental Science, 16, 676-687. doi:10.1111/desc. 12079

Van Dijk, M., van Geert, P., Korecky-Kröll, K., Maillochon, I., Laaha, S., Dressler, W. U., \& Bassano, D. (2013). Dynamic adaptation in child-adult language interaction. Language Learning, 63, 243-270. doi:10.1111/lang.12002

Van Geert, P. (2011). The contribution of complex dynamic systems to development. Child Development Perspectives, 5, 273-278. doi:10. 1111/j.1750-8606.2011.00197.x

Weisleder, A., \& Fernald, A. (2013). Talking to children matters: Early language experience strengthens processing and builds vocabulary. Psychological Science, 24, 2143-2152. doi:10.1177/09567976 13488145 